\title{
RESEARCHES REGARDING EVALUATION OF ENERGY CONSUMPTION FOR MANUFACTURING OF PELLETS FROM VINE PRUNING RESIDUES
}

\author{
Ioan Tenu ${ }^{1}$, Radu Rosca ${ }^{1}$, Petru Carlescu ${ }^{1}$, Cecilia Roman ${ }^{2}$, Lacrimioara Ramona Senila ${ }^{2}$, \\ Vlad Arsenoaia $^{1}$, Dumitrache Emanuil ${ }^{1}$, Baetu Marius ${ }^{1}$, Oana-Raluca Corduneanu ${ }^{1}$ \\ ${ }^{1}$ University of Agricultural Sciences and Veterinary Medicine "Ion Ionescu de la Brad" Iaşi, Romania; \\ ${ }^{2}$ Research Institute for Analytic Instrumentation Cluj-Napoca, Romania \\ itenu@uaiasi.ro,rrosca@uaiasi.ro
}

\begin{abstract}
Renewable energy resources represent real prospects for replacing fossil fuels. Compared to other combustible materials (coal, oil etc.), biomass is widespread and can be found in various forms (wood, woody plants, aquatic, agricultural, waste etc.). Any country on the globe has the possibility and obligation to produce green energy from biomass. Biomass contributes with $14 \%$ to global primary energy consumption, and for three quarters of the world's population living in developing countries it is the most important source of energy. The researches of the present paper were aimed to evaluate the potential of biomass resulting from dry cutting of varieties of vines on the fruit and the energy consumed during the operations of milling, drying and manufacturing of pellets derived from it. All the operations were carried out with equipment designed and realized within the Laboratory of Mechanization of Agriculture, from the University of Agricultural Sciences and Veterinary Medicine "Ion Ionescu de Brad" from Iasi. Following the analyses performed, it was found that the higher calorific value of the vine pruning residues harvested and taken in the study was between 14.49$18.31 \mathrm{MJ} \cdot \mathrm{kg}^{-1}$, and the lower calorific power varies between $13.08 \ldots 16.88 \mathrm{MJ} \cdot \mathrm{kg}^{-1}$, depending on the variety. Considering the specific nature of the vineyard plantation, it turns out that the energy potential of the biomass harvested from one hectare has values between $8746.39 \mathrm{MJ} \cdot(\mathrm{kg} \cdot \mathrm{ha})^{-1}$ and $13603.94 \mathrm{MJ} \cdot(\mathrm{kg} \cdot \mathrm{ha})^{-1}$, equivalent to one quantity of firewood between $696.37 \mathrm{~kg}$ and $812.18 \mathrm{~kg}$. Also, within this work, the energy requirements for conversion of vine pruning residues into densified biomass, as pellets, were evaluated. Thus, a total average electricity consumption of $0.5215-3.4959 \mathrm{MJ}^{-\mathrm{kg}^{-1}}$ was recorded, of which, for coarse chopping 0.0236$0.0306 \mathrm{MJ} \cdot \mathrm{kg}^{-1}$, for grinding particles larger than $4 \mathrm{~mm}, 0.0587 \mathrm{MJ} \cdot \mathrm{kg}^{-1}$, for drying $2.692 \mathrm{MJ} \cdot \mathrm{kg}^{-1}$ and for pelletizing $0.4392 \mathrm{MJ} \cdot \mathrm{kg}^{-1}$.
\end{abstract}

Keywords: solid biofuels, pellets, vine tendrils, energy consumption.

\section{Introduction}

Biomass is one of the most important sources of primary energy, after fossil fuels, providing approximately $14 \%$ of the world energy consumption [1]. The main sources of biomass are agricultural and forest residues, energetic crops, different organic wastes etc.

The interest for conversion of biomass into thermal and/or electric energy is due to the fact that it is a valuable and renewable resource and because it has several advantages regarding the environmental protection [2]. In comparison with other combustible materials (coal, oil etc.), biomass is to be found all over the globe, it is present in different forms (wood, wooden crops, aqueous and agricultural crops, wastes etc.), does not increase the concentration of $\mathrm{CO}_{2}$ in the atmosphere, reduces the global warming effect and does not produce acid rains, because it has a low sulphur content [3]. It is for these reasons that there is an increased interest in developing and improving the technologies used in order to produce green energy from biomass [4; 5]. It is an inexhaustible reserve and an important source of energy for mankind, because during the growing process of the crops, carbon dioxide in the atmosphere and water in the soil, together with the nutritive elements, are harnessed through photosynthesis and turned into carbohydrates that are constitutive elements of biomass. The solar energy is accumulated through photosynthesis into the chemical bonds of the biomass structural elements. Through the combustion of biomass, atmospheric oxygen is combined with carbon in the plants, resulting in carbon dioxide and water. Thus, the process is a cyclic one, carbon dioxide in the atmosphere is being once again absorbed by the plants [3; 4]. It should be mentioned that modern technologies achieve a complete combustion of biomass, and the main combustion products are carbon dioxide $\left(\mathrm{CO}_{2}\right)$ and water $\left(\mathrm{H}_{2} \mathrm{O}\right)$, as the ash, particles and sulphur content is lower compared to fossil fuels and especially coal [6]. Moreover, biomass, as the lignocellulose raw material for producing densified fuels, contains large amounts of elements that promote combustion, such as carbon and hydrogen, and low amounts of elements that do not promote combustion, respectively oxygen, sulphur, nitrogen, water and ash [7]. 
The tendrils resulting from the dormant pruning of vines are also a combustible lignocellulose raw material. The resulted biomass is an important energy source due to the significant level of the high calorific value, which is comprised between $14.49 \mathrm{MJ} \cdot \mathrm{kg}^{-1}$ for the Pinot noir variety and $18.31 \mathrm{MJ} \cdot \mathrm{kg}^{-1}$ for the Feteasca regala variety [8]; from a chemical point of view, this type of biomass has high carbon content, over $43.1 \%$ for all the studied varieties [8]. The vine tendrils contain 24-32\% lignin, 29$40 \%$ cellulose and 17-26\% hemicellulose, depending on the variety [8-10]. The high content of lignocellulose substances is favourable for production of densified biomass in the form of briquettes and pellets.

The aim of the present paper is to present the results of experimental tests regarding the technological conditions for producing pellets from vine tendrils and the required energy consumption.

\section{Materials and methods}

In order to perform the research regarding the optimum technological conditions for production of densified biomass in the form of pellets, tendrils resulting from the dormant pruning of vine were collected. The vineyard belongs to the Didactical Station of the University of Agricultural Sciences and Veterinary Medicine in Iasi (Horticultural Farm "Vasile Adamachi"). The tendrils were collected from the following vine varieties: Sauvignon Blanc; Pinot Noir; Feteasca Alba; Feteasca Reagala; Feteasca Neagra; Busuioaca de Bohotin; Cabernet Sauvignon and Muscat Ottonel.

The densification technology for tendrils, used for obtaining pellets, comprises the following unit operations: course grinding, drying, fine grinding (in order to obtain particles smaller than $4 \mathrm{~mm}$ ) and pelletization of the tendrils (Fig. 1 and Fig. 2).

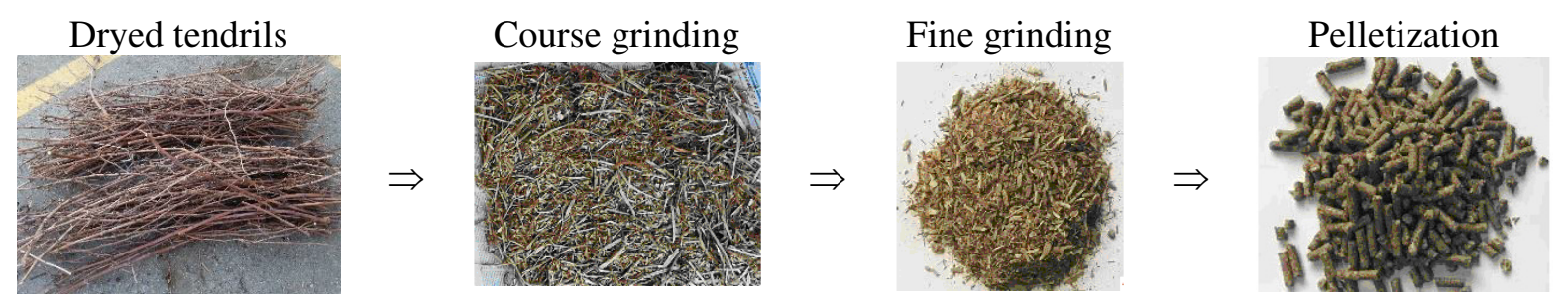

Fig. 1. Technological phases for pelletization of vine tendrils (natural drying)

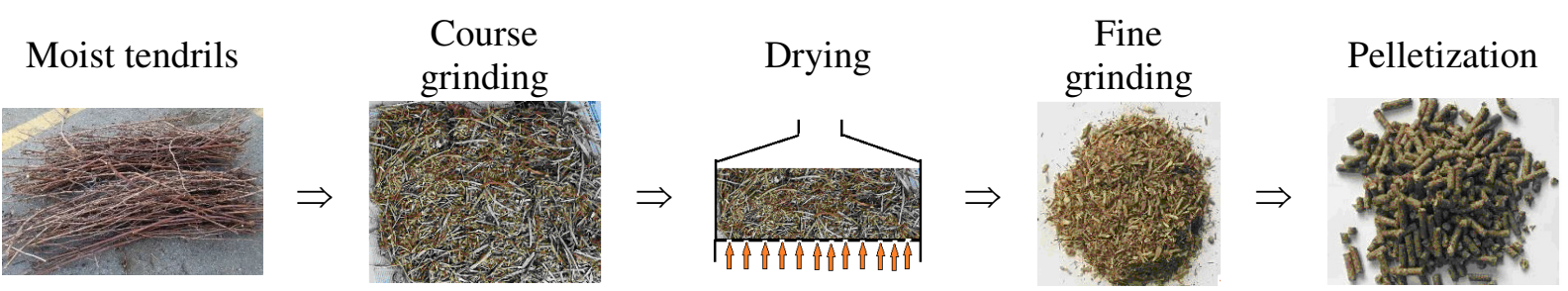

Fig. 2. Technological phases for pelletization of vine tendrils (forced drying)

In order to evaluate the overall energy consumption, the collected tendrils, with a humidity of 44$46 \%$, were dried until the humidity dropped to $12-14 \%$, using one of the following procedures:

- natural drying - the tendrils were deposited for 70 days in an open shed (in order to allow air circulation);

- forced drying, using hot air $\left(70^{\circ} \mathrm{C}, 100^{\circ} \mathrm{C}\right.$ and $\left.120^{\circ} \mathrm{C}\right)$ with the circulation velocity of $0.75 \mathrm{~m} \cdot \mathrm{s}^{-1}$.

The tendrils were grinded with the BIO 90 grinder (Fig. 3), produced by Caravaggi, Italy, aimed to operate with a 30-60 HP tractor; in order to evaluate the energy consumption, the grinder was driven with a $7.5 \mathrm{~kW}$ electric motor. The contraption is equipped with a chopping apparatus containing two rotary blades, a counter-beater. In the first stage the sieve has $15 \mathrm{~mm}$ diameter orifices and the resulting particles have a diameter lower than $50 \mathrm{~mm}$; in the second stage the sieve has $5 \mathrm{~mm}$ orifices and the diameter of the resulting particles is less than $4 \mathrm{~mm}$.

In order to establish the kinetics of the drying process and the energy consumption during the forced drying of tendrils a laboratory installation (Fig. 4) was designed and constructed. The installation has the following features: the cylindrical drying shell (1) has a diameter $\varnothing=440 \mathrm{~mm}$ and 
a height $h=700 \mathrm{~mm}$; the cylindrical biomass hopper (2) has an exterior diameter $\varnothing_{e}=280 \mathrm{~mm}$, an interior diameter $\emptyset_{i}=110 \mathrm{~mm}$ and the height $h=540 \mathrm{~mm}$, allowing the drying of a $5-7 \mathrm{~kg}$ biomass charge. The drying agent is prepared in a hot-gas recycling system, equipped with the adjustable flaps (12 and 13), which are used in order to adjust the recycle air flow and the discharged air flow, respectively. In order to obtain a uniform distribution of the drying agent, the air feeding connection (19) is tangent to the drum. Electric resistance (14) is used to heat the air; the electric power of the resistance is $2500 \mathrm{~W}$ and it is provided with fins for better heat transfer.

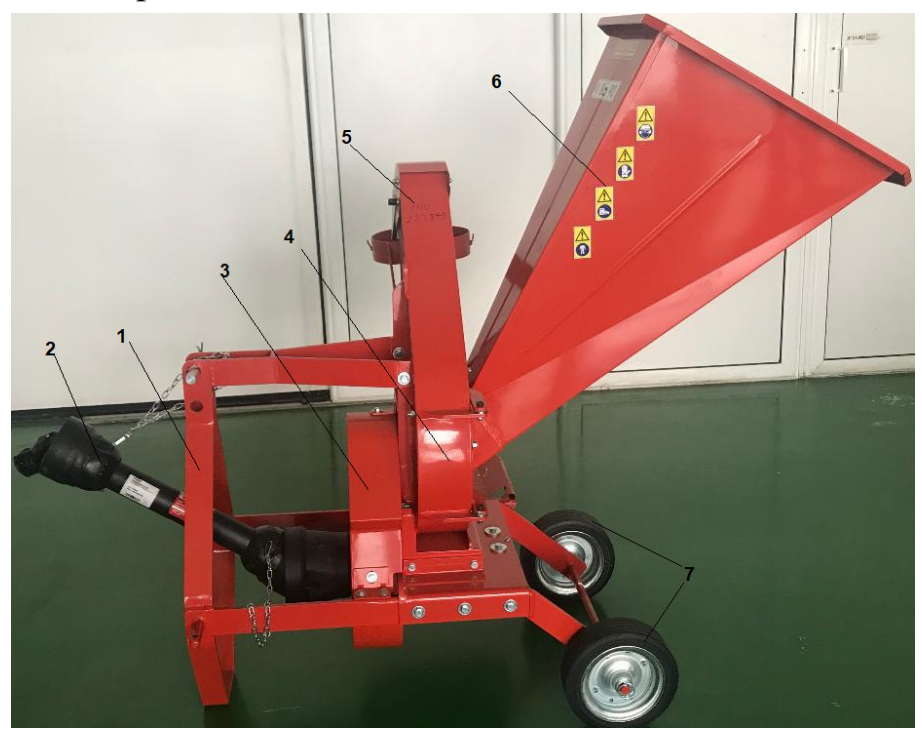

Fig. 3. BIO 90 grinder: 1 - frame, with 3 point hitch strut; 2 - universal joints transmission; 3 - belt transmission; 4 - grinding device; 5 - grinded material chute; 6 - feeding chute

a)

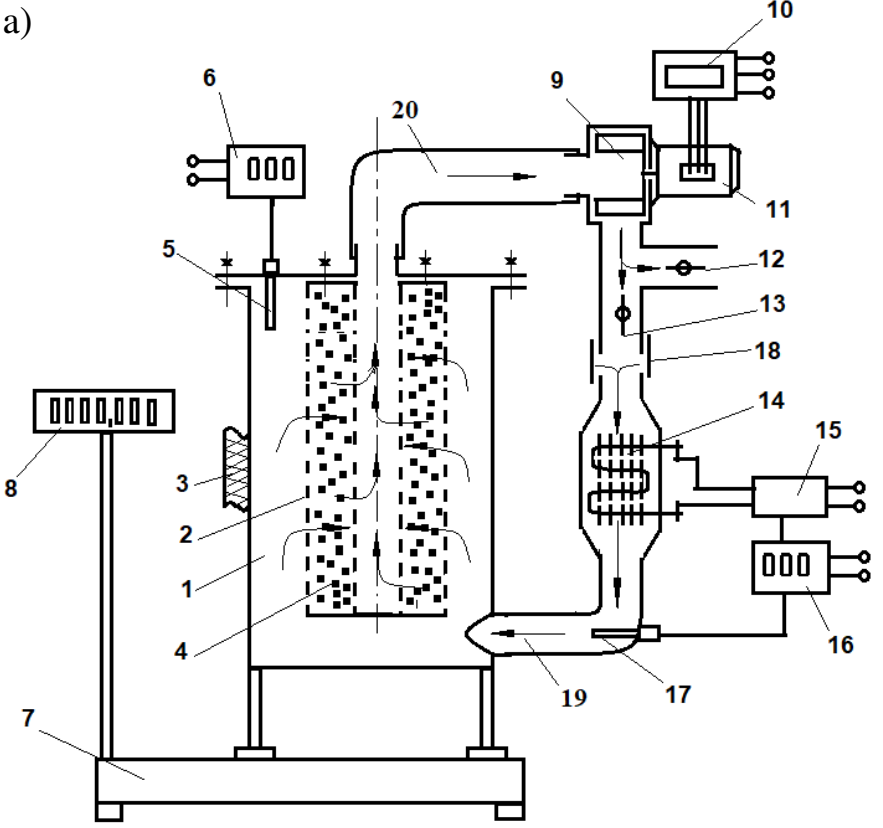

b)

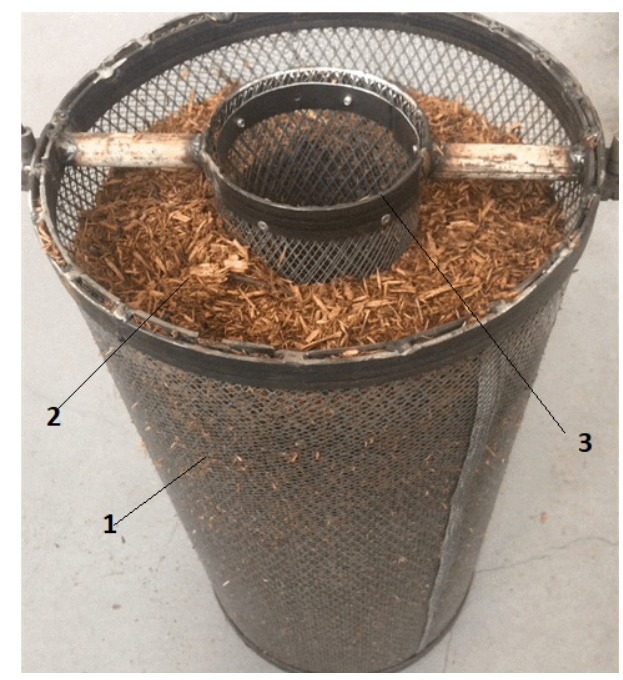

Fig. 4. Laboratory test rig for drying of grinded tendrils: a - general schematics ( 1 - drying drum; 2 - grinde biomass chute; 3 - insulation; 4 - grinded tendrils; 5 - anemometer; 6 - hot wire probe; 7 - scale; 8 - display; 9 - centrifugal fan; 10 - VFD; 11 - electric motor; 12, 13 - adjustable flaps;

14 - heating resistance; 15 - relay; 16 - thermostat; 17 - RTD probe; 18 - air intake orifices; 19 - fresh hot air feeding pipe; 20 - used hot air intake pipe); $b$ - biomass drum ( 1 - outer casing; 2 - grinded tendrils; 3 - hot air central pipe)

The drying equipment is provided with automation devices, which allow adjustment of the velocity of the drying agent (by modifying the speed of the motor driving the fan) and monitoring of 
the operating parameters, such as the thermostat with the RTD temperature transducer (16 and 17), anemometer and the hot wire probe (5 and 6), electronic scale for measuring the quantity of evaporated water. In order to diminish heat losses, the entire equipment is thermally insulated.

Pelletization of the grinded tendrils was performed using the pelletizing equipment (Fig. 5a) with a rotating horizontal matrix and two cylindrical rollers for the extrusion (Fig. 5b). The equipment has the following characteristics: operating capacity $80-120 \mathrm{~kg} \cdot \mathrm{h}^{-1}$; matrix diameter $170 \mathrm{~mm}$; diameter of the matrix orifices $6 \mathrm{~mm}$; roller with $98 \mathrm{~mm}$ diameter and a width of $40 \mathrm{~mm}$; power of the electric driving motor $-7.5 \mathrm{~kW}$. The rollers are free mounted on a spindle, which is provided with a device allowing the adjustment of the pressure between the rollers and the matrix.

a)

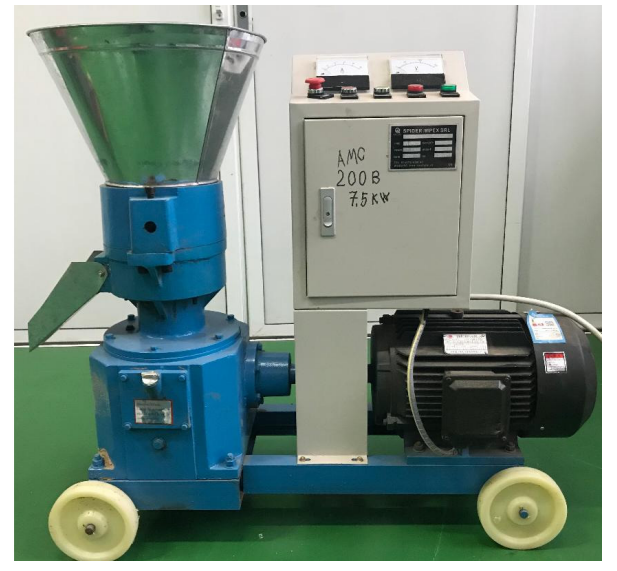

b)

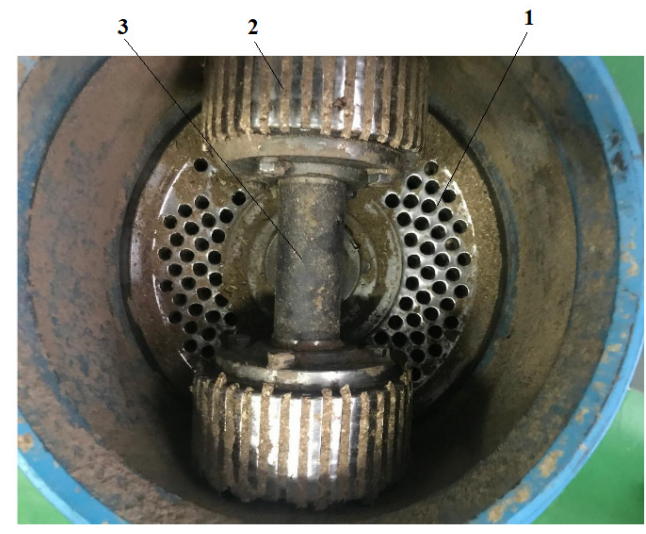

Fig. 5. Pelletizing equipment: $a-$ general view; $b$ - operating parts of the equipment (1 - matrix; 2 - cylindrical rollers; 3 - spindle)

The water mass fraction of the grinded tendrils, ready for pelletization, was $12 \pm 0.5 \%$. This value of the humidity was adopted after some initial tests were performed in order to achieve the pelletization ratio over $90 \%$. It should be noted that specialized literature indicates that, in order to obtain superior quality pellets, the water content of the grinded raw material should be comprised between 11 and $13 \%[7 ; 11]$ in order to achieve the cohesion bonds among the compacted particles.

A thermobalance with the following features was used in order to measure the water content: max. drying temperature $160{ }^{\circ} \mathrm{C}$; precision: sample mass $0.1-5 \mathrm{~g} \pm 0.3 \%$; sample mass 5$15 \mathrm{~g} \pm 0.06 \%$; sample mass $>15 \mathrm{~g} \pm 0.04 \%$. Tendrils dehydration was performed at $105^{\circ} \mathrm{C}$ [12].

The operating parts of the matrix were heated to more than $110^{\circ} \mathrm{C}$ before pelletization in order to achieve proper densification conditions, respectively, temperatures above $130{ }^{\circ} \mathrm{C}$ inside the pellet, due to friction [12-14].

After the tendrils were pelletized, the following parameters were evaluated: pelletization ratio, mechanical durability of the pellets, dimensions of the pellets (diameter and length), bulk density and unit density of the pellets.

The pelletization ratio $\left(G_{p}\right)$ was evaluated by sieving the pellets through a sieve according to the SR EN ISO 17831-1 standard: cage diameter - $400 \mathrm{~mm}$; round orifices with a diameter of $3.15 \mathrm{~mm}$ [12]. The initial sieved sample $\left(m_{p i}\right)$, obtained through pelletization, was split into two components: pellets that remained on the sieve $\left(m_{p}\right)$, larger than $3.15 \mathrm{~mm}$, and fragments that passed through the orifices of the sieve. The initial sample and the pellets larger than $3.15 \mathrm{~mm}$ were weighted on an electronic scale (precision $0.01 \mathrm{~g}$ ) and the pelletization ratio was calculated with the formula:

$$
G_{p}=\frac{m_{p}}{m_{p i}} \times 100 \% \text {. }
$$

A calibrated $1 \mathrm{dm}^{3}$ aluminium cylinder was used in order to evaluate the bulk density; the interior diameter of the cylinder was $88 \mathrm{~mm}$ and its height was $164.5 \mathrm{~mm}$. The same electronic scale was used in order to weight the sample [12].

Unit density was evaluated with the picnometer method for measuring the relative density [12]. 
Mechanical durability of the pellets was evaluated according to the method presented in SR EN ISO 17831-1:2016 standard, using the device shown in Fig. 6.

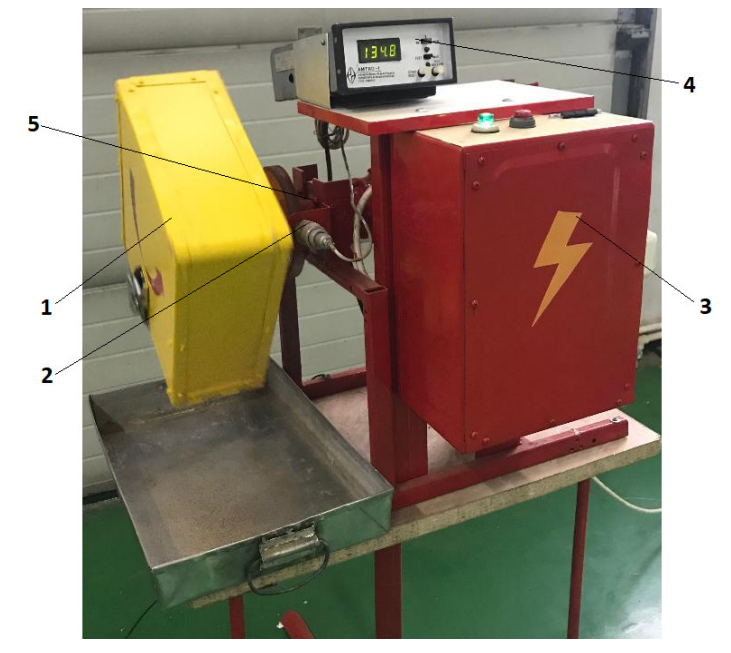

Fig. 6. Equipment for evaluation of durability of the pellets, according to

SR EN ISO 17831-1/2016: 1 - sealed box; 2 - speed sensor; 3 - electric panel; 4 - tachometer; 5 - reduction gear [12]

The device is comprised of a sealed box $(L=300 \mathrm{~mm} ; W=300 \mathrm{~mm} ; H=125 \mathrm{~mm})$; the box has an interior baffle and a driving mechanism. A tachometer is used to measure the number of rotations and the rotation speed of the box.

The tested sample $(500 \pm 10 \mathrm{~g})$ is loaded into the box and the box is then rotated with $50 \pm 2 \mathrm{rpm}$ (500 revolutions - [12]). Then the pellets are sieved, using the same sieve as for the pelletization ratio. The sample is weighted before the test $\left(m_{i}\right)$; after the test, the pellets retained by the sieve are also weighted $\left(\mathrm{m}_{\mathrm{f}}\right)$; the mechanical durability $(D U)$ is calculated with the formula:

$$
D U=\frac{m_{f}}{m_{i}} \times 100 \% \text {. }
$$

The samples which were tested were prepared according to the requirements of the SR EN ISO 17831-1/2016 standard: an amount of $2 \mathrm{~kg}$ of pellets was split into four equal samples. One sample was used to evaluate the water content and the other three samples were used to perform the mechanical durability test in 3 replicates [12].

In order to evaluate the energy consumption for each technological operation, the equipment and machines were powered from the electrical grid by means of a single phase power meter, type Energy Logger 4000 (Fig. 7a); for the three phase consumers, three single phase energy meters were used (Fig. 7b). This type of power meter measures and records the energy consumption on a SD card; the recorded data are then downloaded to the computer using proprietary software and then exported into a MS Excel spreadsheet.

\section{Results and discussion}

The experimental tests were performed according to the procedures presented above and were aimed to evaluate the technological conditions for densification of vine tendrils as pellets. The densification process comprised two stages: preparation of the raw material (harvesting, natural dehydration and grinding of the tendrils) and pelletization.

The dimensions of the pellets were in accordance with the requirements of the ISO 17829 standard: the average diameter was $6 \pm 0.5 \mathrm{~mm}$ and the length was between 3.15 and $40 \mathrm{~mm}$.

The pelletization ratio reveals that the pelletization process was successful; its values were between $93.13 \%$ for Feteasca Alba variety and $94.65 \%$ for the variety Feteasca Regala. The differences are due to the fact that different vine varieties have different contents of lignocelluloses and different textures.

Bulk density and unit density are important features of densified biofuels. The analysis of the results regarding the bulk density led to the conclusion that this item recorded values were between 
$682.83 \mathrm{~kg} \cdot \mathrm{m}^{-3}$ for the variety Feteasca Regala and $612.32 \mathrm{~kg} \cdot \mathrm{m}^{-3}$ for the variety Cabernet, thus exceeding the limits imposed by the ISO 17828 standard. The unit density of the pellets was between $1045.15 \mathrm{~kg} \cdot \mathrm{m}^{-3}$ for Cabernet Sauvignon and $1227.31 \mathrm{~kg} \cdot \mathrm{m}^{-3}$ for Feteasca Regala.

a)

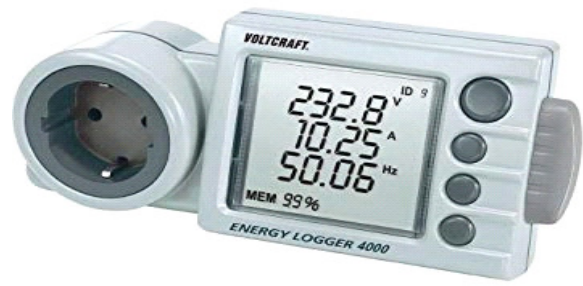

b)

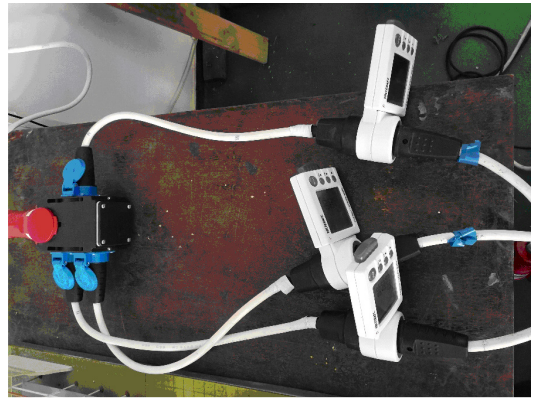

Fig. 7. Energy Logger 4000 type power meter: a - single phase consumer; $b$ - three phase consumer

The mechanical durability of the pellets defines the conservation conditions of the final product throughout the commercial chain. This parameter was evaluated performing experimental tests, which simulate the mechanical stress of the pellets throughout the storage, transportation and handling chains. The experimental results show that the values of mechanical durability of the pellets obtained from vine tendrils (Table 1) fulfil the quality requirements imposed by the ISO 17225-6/2014 standard for all vine varieties. It should be mentioned that this is true only when the temperature inside the pellets exceeds $130^{\circ} \mathrm{C}[12]$.

Table 1

Mechanical durability and water content of pellets from vine tendrils

\begin{tabular}{|c|c|c|c|c|c|c|c|c|}
\hline \multirow{2}{*}{ Item } & \multicolumn{9}{|c|}{ Vine variety } \\
\cline { 2 - 9 } & $\begin{array}{c}\text { Busuioaca } \\
\text { de Bohotin }\end{array}$ & $\begin{array}{c}\text { Cabernet } \\
\text { Sauvignon }\end{array}$ & $\begin{array}{c}\text { Feteasca } \\
\text { Alba }\end{array}$ & $\begin{array}{c}\text { Feteasca } \\
\text { Neagra }\end{array}$ & $\begin{array}{c}\text { Feteasca } \\
\text { Regala }\end{array}$ & $\begin{array}{c}\text { Muscat } \\
\text { Ottonel }\end{array}$ & $\begin{array}{c}\text { Pinot } \\
\text { Noir }\end{array}$ & $\begin{array}{c}\text { Sauvignon } \\
\text { Blanc }\end{array}$ \\
\hline $\begin{array}{c}\text { Durability, } \\
\%\end{array}$ & 97.6 & 97.8 & 97.5 & 97.7 & 97.7 & 97.5 & 97.6 & 97.7 \\
\hline $\begin{array}{c}\text { Water } \\
\text { content, } \\
\%\end{array}$ & 9.62 & 9.34 & 9.45 & 9.68 & 9.74 & 9.86 & 9.88 & 9.74 \\
\hline
\end{tabular}

In order to evaluate the overall energy consumption for densification of vine tendrils all the phases of the technological process were accounted for. Thus, in order to transform biomass into raw material for pelletization, with the dimension of the particles lower than $4 \mathrm{~mm}$, the grinding process of the tendrils from the variety Feteasca Regala was studied for both the tendrils with the water content of $44.24 \%$ and for the dehydrated ones with $11.25 \%$ water content. The results referring to the energy consumption for coarse grinding are presented in Table 2, while those for fine grinding are shown in Table 3; for each grinding stage $20 \mathrm{~kg}$ of material were processed.

Table 2

Fractions and energy consumption for coarse grinding of vine tendrils

\begin{tabular}{|c|c|c|c|c|c|c|c|c|c|c|}
\hline \multirow{3}{*}{$\begin{array}{c}\text { Water } \\
\text { content, } \\
\%\end{array}$} & \multirow{3}{*}{$\begin{array}{c}\text { Quantity, } \\
\text { kg }\end{array}$} & \multicolumn{8}{|c|}{ Grinded fractions } & \multirow{3}{*}{$\begin{array}{c}\text { Energy } \\
\text { consumption, } \\
\mathbf{M J} \cdot \mathbf{k g}^{-1}\end{array}$} \\
\hline & & \multicolumn{2}{|c|}{$>50 \mathrm{~mm}$} & \multicolumn{2}{|c|}{$15-50 \mathrm{~mm}$} & \multicolumn{2}{|c|}{ 4-15 $\mathrm{mm}$} & \multicolumn{2}{|c|}{$<4 \mathrm{~mm}$} & \\
\hline & & $\mathrm{kg}$ & $\%$ & $\mathrm{~kg}$ & $\%$ & $\mathrm{~kg}$ & $\%$ & $\mathrm{~kg}$ & $\%$ & \\
\hline 44.25 & 20.00 & 4.25 & 21.25 & 8.83 & 44.15 & 5.42 & 27.1 & 1.5 & 7.5 & 0.0306 \\
\hline 11.25 & 20.00 & 3.15 & 15.73 & 5.47 & 27.33 & 6.93 & 34.67 & 4.45 & 22.27 & 0.0236 \\
\hline
\end{tabular}

The size of the particles resulted from coarse grinding strongly depends on the water content of the tendrils; thus, for the dehydrated material, over $22 \%$ of the particles were smaller than $4 \mathrm{~mm}$, while the specific energy consumption decreased from $0.0306 \mathrm{kWh} \cdot \mathrm{kg}^{-1}$ to $0.0236 \mathrm{kWh} \cdot \mathrm{kg}^{-1}$.

A mass of $20 \mathrm{~kg}$ of coarse grinded tendrils was used for fine grinding, with particles with a diameter larger than $4 \mathrm{~mm}$. 
In the case of fine grinding, the operating process is substantially improved for the dehydrated tendrils, both in terms of particle dimension and energy consumption; thus, the energy consumption has decreased by $30 \%$ and the amount of material that imposes supplementary grinding has decreased by $10 \%$.

Table 3

Fractions and energy consumption for fine grinding of vine tendrils

\begin{tabular}{|c|c|c|c|c|c|c|c|c|c|c|}
\hline \multirow{3}{*}{$\begin{array}{c}\text { Water } \\
\text { content, } \\
\%\end{array}$} & \multirow{3}{*}{$\begin{array}{c}\text { Quantity, } \\
\text { kg }\end{array}$} & \multicolumn{8}{|c|}{ Grinded fractions } & \multirow{3}{*}{$\begin{array}{c}\text { Energy } \\
\text { consumption, } \\
\mathrm{MJ} \cdot \mathrm{kg}^{-1}\end{array}$} \\
\hline & & \multicolumn{2}{|c|}{$>10 \mathrm{~mm}$} & \multicolumn{2}{|c|}{ 6-8 mm } & \multicolumn{2}{|c|}{ 4-6 mm } & \multicolumn{2}{|c|}{$<4 \mathrm{~mm}$} & \\
\hline & & $\mathrm{kg}$ & $\%$ & $\mathrm{~kg}$ & $\%$ & $\mathrm{~kg}$ & $\%$ & $\mathrm{~kg}$ & $\%$ & \\
\hline 44.25 & 20 & 1.82 & 9.46 & 2.52 & 12.59 & 4.24 & 21.2 & 11.35 & 56.75 & 0.0860 \\
\hline 11.25 & 20.00 & 1.47 & 7.37 & 1.98 & 9.86 & 3.96 & 19.81 & 12.59 & 62.96 & 0.0587 \\
\hline
\end{tabular}

For the same vine variety as above (Feteasca Regala), the effect of the temperature of the drying agent over the dehydration process was studied. Three temperatures of the drying agent were used $\left(70{ }^{\circ} \mathrm{C}, 100{ }^{\circ} \mathrm{C}\right.$ and $\left.120^{\circ} \mathrm{C}\right)$ and the results are shown in Table 4 .

Table 4

Dehydration kinetics and energy consumption for drying vine tendrils $\mathrm{C}$

\begin{tabular}{|c|c|c|c|c|c|c|c|c|c|}
\hline \multirow{2}{*}{$\begin{array}{c}\text { Drying } \\
\text { agent } \\
\text { temp. } \\
{ }^{\circ} \mathrm{C}\end{array}$} & \multirow{2}{*}{$\begin{array}{c}\text { Drying } \\
\text { time to } \\
11-12 \% \\
\text { water } \\
\text { content, } \\
\text { min }\end{array}$} & \multicolumn{2}{|c|}{$\begin{array}{l}\text { Mass of the } \\
\text { sample, } g\end{array}$} & \multicolumn{2}{|c|}{$\begin{array}{c}\text { water } \\
\text { content, \% }\end{array}$} & \multirow{2}{*}{$\begin{array}{l}\text { Amount of } \\
\text { evaporated } \\
\text { water, } g\end{array}$} & \multirow{2}{*}{$\begin{array}{l}\text { Dehydration } \\
\text { velocity } \\
\mathrm{g} \mathrm{H}_{2} \mathrm{O} \cdot(\mathbf{h} \cdot \mathrm{kg} \\
{\text { biomass })^{-1}}^{-n^{2}}\end{array}$} & \multirow{2}{*}{$\begin{array}{c}\text { Energy } \\
\text { consumption } \\
\text { kW }\end{array}$} & \multirow{2}{*}{$\begin{array}{c}\text { Specific } \\
\text { energy } \\
\text { consumption } \\
\mathbf{M J} \cdot \mathbf{k g}^{-1}\end{array}$} \\
\hline & & Initial & Final & Initial & Final & & & & \\
\hline 70 & 240 & 66 & 4474 & & 11. & & & & \\
\hline 10 & & & & & & & & & \\
\hline 120 & 145 & 6842 & 4585 & 44.56 & 11.58 & 2257 & 136.5 & 5.513 & 2.901 \\
\hline
\end{tabular}

The results referring to the energy consumption for production of pellets are shown in Table 5 (for $10 \mathrm{~kg}$ of grinded tendrils)

Table 5

Energy consumption and duration for pelletization of $10 \mathrm{~kg}$ of grinded tendrils, variety Feteasca Regala

\begin{tabular}{|c|c|c|c|}
\hline $\begin{array}{c}\text { Overall energy } \\
\text { consumption, } \\
\mathbf{k W h}\end{array}$ & $\begin{array}{c}\text { Pelletization } \\
\text { time, } \mathbf{m i n}\end{array}$ & $\begin{array}{c}\text { Energy consumption } \\
\text { per unit of biomass, } \\
\mathbf{~} \mathbf{W h} \cdot \mathbf{k g}^{-1}\end{array}$ & $\begin{array}{c}\text { Specific energy } \\
\text { consumption, } \\
\mathbf{M J} \cdot \mathbf{k g}^{-1}\end{array}$ \\
\hline 1.22 & 8.36 & 0.122 & 0.4392 \\
\hline
\end{tabular}

The data in Table 6 summarize the energy consumption for densification of tendrils, based on the two drying technologies (normal dehydration and forced dehydration) for Feteasca Regala variety. The results clearly show that the energy consumption for the forced dehydration of tendrils is 6 times higher than for the normal dehydration.

Table 6

Energy consumption for producing pellets from vine tendrils

\begin{tabular}{|c|c|c|c|c|c|}
\hline \multirow[b]{2}{*}{$\begin{array}{l}\text { Technological } \\
\text { variant }\end{array}$} & \multicolumn{4}{|c|}{ Energy consumption for the technological phases } & \multirow{2}{*}{$\begin{array}{c}\text { Overall } \\
\text { energy } \\
\text { consumption, } \\
\mathbf{M J} \cdot \mathbf{k g}^{-1} \\
\end{array}$} \\
\hline & $\begin{array}{c}\text { Coarse } \\
\text { grinding, } \\
\text { MJ } \cdot \mathbf{k g}^{-1}\end{array}$ & $\begin{array}{c}\text { Forced } \\
\text { dehydration, } \\
\text { MJ } \mathbf{k g}^{-1}\end{array}$ & 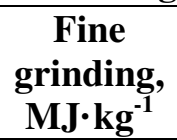 & $\begin{array}{c}\text { Pelletization, } \\
\mathrm{MJ} \cdot \mathrm{kg}^{-1}\end{array}$ & \\
\hline $\begin{array}{c}\text { Normal } \\
\text { dehydration }\end{array}$ & 0.0236 & 0 & 0.0587 & 0.4392 & 0.5215 \\
\hline $\begin{array}{c}\text { Forced } \\
\text { dehydration }\end{array}$ & 0.0306 & $2.692 *$ & 0.0587 & 0.4392 & 3.4959 \\
\hline
\end{tabular}

*air temperature: $100{ }^{\circ} \mathrm{C}$. 


\section{Conclusions}

1. The use of renewable energy sources is a necessity for the present and future of civilization, as biomass is one of the maim raw materials for production of energy.

2. The tendrils produced as a consequence of dormant pruning of vine are also lignocellulose raw materials; they have high calorific value and are an important source of energy.

3. The research was aimed to establish the technological conditions for producing densified biomass in the form of pellets from tendrils resulted from the dormant pruning of vine. All the phases of the technological process for obtaining pellets were taken into account.

4. Specific equipment for production of pellets was designed or purchased in order to measure all the parameters that define the quality indices of the pellets and the energy consumption for their production.

5. The quality of the pellets produced from vine tendrils fulfils the requirements of the SR EN ISO 17225-6-2014 standard.

6. The results regarding the energy consumption for the production of pellets indicate that normal dehydration, due to free flow of atmospheric air, is the optimum variant with regard to the energy requirements.

\section{Acknowledgement}

This work was supported by a grant of the Romanian Ministry of Research and Innovation. CCCDIUEFISCDI, project number PN-III-P1-1.2-PCCDI-2017-0251/4PCCDI/2018, within PNCD III.

\section{References}

[1] Purohit P, Kandpal T.C., Tripathi A. K. Energetics of coal substitution by briquettes of agricultural residues, Energy, Volume 31, Issues 8-9, July 2006, pp. 1321-1331.

[2] Perlack R.D., Wright L.L. Technical and economic status of wood energy feedstock production. Energy, Volume 20, Issue 4, April, 1995, pp. 279-284.

[3] Houghton R.A., Hall J. F., Goetz S. Importance of biomass in the global carbon cycle, Journal of Geophysical Research, vol. 114, 2009, pp. 1-13.

[4] Marian, G., Țenu, I., Roșca, R., Gudîma, A. Pavlenco, A. Assessment of the quality of secondary production from different agricultural crops used as primary material for densified solid biofuels, Scientifc Papers - Agronomy Series, vol. 62 (1), 2019, pp. 97-101.

[5] Muntean A., Havrland B,. Pobedinsky V., Ivanova T., Marian G. Features of bio-briquettes pressing with the piston briquetting press. Proceedings of the 9th International Scientific conference: engineering for rural development, 2010, Book Series: Engineering for Rural Development, pp. 246-251.

[6] Bhattacharya S.C., Salam P.A. Low greenhouse gas biomass options for cooking in the developing countries. Biomass Bioenerg, vol. 22, 2002, pp. 305-331.

[7] Obernberger I., Thek G. Physical characterisation and chemical composition of densified biomass fuels with regard to their combustion behavior. Biomass and Bioenergy, vol.27, 2004, pp. 185191.

[8] Țenu I., Dumitrachi P.E., Roșca R., Cârlescu P., Naghiu A., Roman Cecilia, Senila Lacrimioara Ramona, Becze Anca. Researches regarding the evaluation of the biomass potential resulted from the dormant pruning of some vine varieties. Proceedings of the International Symposium ISBINMA TEH 2018, November 1-3, 2018, Bucharest, Romania, pp. 155-123.

[9] Amendola D., Faveri D.M., Egües, I. Serrano L., Labidi J., Spigno G. Autohydrolysis and organosolv process for recovery of hemicelluloses, phenolic compounds and lignin from grape stalks. Bioresource Technology, vol. 107, 2012, pp. 267-274.

[10] Spigno G., Maggi L., Amendola D., Dragoni M., De Faveri D.M. Influence of cultivar on the lignocellulosic fractionation of grape stalks. Industrial Crops and products, vol. 46, 2013, pp. 283289.

[11] Samuelsson R., Larsson S., Thyrel M., Lestander T. A. Moisture content and storage time influence the binding mechanisms in biofuel wood pellets. Applied energy, vol. 99, 2012, pp. 109-115. 
[12] Țenu I., Corduneanu O. R., Roșca R., Cârlescu P., Stoleru V., Naghiu A., Roman C.

[13] Biswas A. K, Rudolfsson M., Broström M., Umeki K. Effect of pelletizing conditions on combustion behaviour of single woodpellet, Applied Energy, vol. 119, 2014, pp. 79-84.

[14] Nielsen N.P., Gardner D., Poulsen T., Felby C. Importance of temperature, moisture content and species for the conversion process of wood residues into fuel pellets. Wood and Fiber Science, vol. 41(4), 2009, pp. 414-425. 